\title{
Daily lying behavior of lactating Holstein cows during an estrus synchronization protocol and its associations with fertility
}

\author{
B. F. Silper, ${ }^{*}$ A. M. L. Madureira, ${ }^{\star} †$ L. B. Polsky, ${ }^{\star}$ S. Soriano,‡ A. F. Sica,‡ J. L. M. Vasconcelos,† \\ and R. L. A. Cerri*1 \\ *Applied Animal Biology, Faculty of Land and Food Systems, University of British Columbia, Vancouver, BC V6T 1Z4, Canada \\ †Department of Animal Production, São Paulo State University, Botucatu, SP 18168-000, Brazil \\ ¥Colorado Farm, Araras, SP 13600-970, Box 286, Brazil
}

\section{ABSTRACT}

Objectives were to quantify lying behavior (LB) during an estradiol and progesterone-based synchronization protocol, to assess risk factors for ovulation, pregnancy per $\mathrm{AI}(\mathrm{P} / \mathrm{AI})$, and degree of behavioral change at estrus, and to investigate the associations between estrus LB and walking activity. Holstein cows (43.6 \pm $11.0 \mathrm{~kg}$ of milk/d) were fitted with leg-mounted accelerometers. Total lying time/d (L_time), bout frequency (bout_N), average lying bout duration, and relative increase in walking activity (ACT\%) were evaluated for 1,411 timed artificial insemination events. The day with lowest L_time or bout_N among $\mathrm{d}-2,-1$, and 0 (day of timed artificial insemination) determined the day of behavioral estrus. The variables L_time $\%$ and bout_N\% represent relative ratios between lowest $\mathrm{L}_{-}$ time and baseline $(\mathrm{d}-7)$, L_time, and lowest bout_N, and baseline $(\mathrm{d}-7)$ bout_N, respectively [e.g., (lowest L_time/baseline L_time) $\times 100]$. Correlation coefficients between L_time\% and bout_N\% and ACT\% were -0.38 and -0.31 , respectively. Estrus LB change was considered large if $<75 \%$ of baseline and small if $\geq 75 \%$ of baseline for both L_time\% and bout_N\%; average lying bout duration did not change with estrus. Lowest L_time\% and bout_N\% corresponded to, respectively, $65 \pm 21 \%$ (mean \pm standard deviation; $447 \pm 157 \mathrm{~min} / \mathrm{d})$ and $65 \pm 24 \%(8.5 \pm 4.0$ bouts/d $)$ of baseline. The change in L_time\% at estrus was smaller when cows had milk yield above average; the change in bout_N\% was smaller among multiparous cows and for estrus occurring in the colder season. Likelihood of ovulation was greater when there was larger change in L_time $\%$ [odds ratio $=4.9$; ovulation rate $=93$ (large change) and $76 \%$ (small change)], as well as when a corpus luteum was present at start of protocol (odds ratio $=3.6$; in the model with L_time\%). Likelihood

Received October 15, 2016.

Accepted June 19, 2017.

${ }^{1}$ Corresponding author: ronaldo.cerri@ubc.ca of pregnancy at d 32 was 1.6 times greater for estrus with large change in $\mathrm{LB}$ [L_time\% or bout_N\%; P/ $\mathrm{AI}=34 \%$ (large change in L_time\%) and $26 \%$ (small change in L_time\%)]. Among estrus events with ACT\% $\geq 300 \%$ (high intensity), classification by small or large L_time\% did not influence P/AI at $32 \mathrm{~d}$. The magnitude of LB change at estrus and its association with fertility suggest potential application toward improved use of activity monitors (e.g., increased estrus detection, fertility prediction). The contribution of LB to accuracy of estrus detection when physical activity is known remains to be addressed. The relationship between intensity of estrus expression and fertility requires further investigations of its physiological rationale and on-farm applications.

Key words: automated detection, estrus intensity, fertility, lying behavior

\section{INTRODUCTION}

Current precision dairy farming technologies allow for automated detection of estrus using tools that record different parameters of animal behavior. In a review of the literature, Rutten et al. (2013) found 48 types of sensors applied to fertility management (e.g., estrus detection), where $61 \%$ measured aspects of cow activity. Restlessness is an important component of behavioral estrus (Roelofs et al., 2010). Although subjective if visually evaluated, restlessness can be quantified through measurements of steps, neck movements, lying time, and bout frequency, for example. Estrus walking activity and neck movements have been researched regarding patterns (Løvendahl and Chagunda, 2010; Valenza et al., 2012) and associations with environmental and cow factors, endocrine profiles, ovulation timing, and fertility (López-Gatius et al., 2005; Stevenson et al., 2014; Aungier et al., 2015; Madureira et al., 2015). Lying behavior, on the other hand, is more frequently employed in cow comfort and welfare assessments (von Keyserlingk et al., 2012; Charlton et al., 2014). Even though reports of its application toward estrus 
detection are rare (e.g., see Rutten et al., 2013), lying behavior has recently been deemed as a useful predictor of estrus (Dolecheck et al., 2015). Research from our group reported a decrease in lying time of $36 \%$ at the day of estrus in nulliparous animals (Silper et al., 2015a).

Expression of estrus (compared with absence of it) at the moment of timed AI (TAI) has been associated with greater pregnancy per AI [P/AI; Cerri et al., 2004 (Heatsynch protocol); Souza et al., 2007 (Ovsynch protocol with injection of $1 \mathrm{mg}$ of estradiol $17-\beta 8 \mathrm{~h}$ before the last $\mathrm{GnRH})]$. Among cows that expressed estrus, those with a higher degree of intensity as measured by automated activity monitors (AAM) were associated with greater P/AI compared with poorly expressed events (Madureira et al., 2015). Pregnancy per AI was also greater among cows with confirmed ovulation after TAI (Pereira et al., 2014). Estrus expression and fertility likely share endocrine regulators. Possible mechanisms could involve progesterone exposure and the regulation of endometrial estradiol receptors $\alpha$ (Spencer et al., 2004), LH concentration and follicular growth (Cerri et al., 2011a,b), in addition to plasma estradiol concentration.

Estradiol and progesterone-based protocols are more likely to induce expression of estrus when compared with GnRH-based protocols (Pereira et al., 2013), providing an opportunity to study the associations between intensity of estrus and fertility under controlled conditions. Automated activity monitors allow grading of behavioral estrus, measurements that can be further used as real-time predictors of fertility and reproductive states. The objectives of our research were to measure the change in lying behavior during an estradiol and progesterone-based synchronization protocol and to assess risk factors associated with the degree of behavioral change at estrus, ovulation, and P/AI. In addition, we aimed to investigate the relationship between measurements of activity and lying behavior. Given the knowledge of increased physical activity at estrus, we hypothesized that lying behavior at estrus would be characterized by reduced lying time and bout frequency and would be negatively correlated with activity. We also hypothesized that the magnitude of change in lying behavior would be associated with ovulation rate and P/AI, similarly to previously reports, when estrus intensity was determined by physical activity.

\section{MATERIALS AND METHODS}

\section{Cows, Housing, and Management}

This study took place at a commercial dairy (São Paulo, Brazil) between July 2013 and June 2014. At the time of the experiment, the herd had an average of 1,700 lactating cows and 305-d average yield of 11,438 $\mathrm{kg}$. Cows were housed in a cross-ventilated freestall barn in groups of 300 animals and milked 3 times daily (at approximately 0500, 1300, and $2100 \mathrm{~h}$ ). The barn had grooved concrete floors and 2 rows of deep sandbedded stalls. Fresh TMR balanced to meet or exceed the nutritional requirements of lactating dairy cows producing $40 \mathrm{~kg}$ of 3.5\% FCM per day (NRC, 2001) was provided thrice daily. Water and TMR were available for ad libitum intake. Experimental procedures followed requirements and practices outlined in the Guide for the Care and Use of Agricultural Animals in Agricultural Research and Teaching (FASS, 1999). Procedures were performed while the cows were restrained in headlocks at the feed bunk after the first daily milking.

\section{Synchronization Protocol, Exams, and Blood Sampling}

Eligible cows (first AI or after negative pregnancy diagnosis, determined apt for breeding by the herd veterinarian) were enrolled onto an ovulation synchronization protocol according to Pereira et al. (2015; Figure 1 ). Timed AI was done using commercial frozen-thawed semen. Ovaries were examined by ultrasonography at $\mathrm{d}-11$ (presence or absence of corpus luteum; CL), 0 (assessment of largest preovulatory follicle), and 7 (presence or absence of CL to confirm ovulation). Positive pregnancy diagnosis required presence of amniotic vesicle with viable embryo (visible heartbeat). Body condition score ( 1 to 5 scale at 0.25 increments; Wildman et al., 1982) was recorded at TAI. Milk production was recorded at each milking (AfiLite, Kibbutz Afikim, Israel).

Blood samples were collected at TAI by puncture of the medial coccygeal artery or vein into $10-\mathrm{mL}$ nontreated Vacutainer tubes (BD, São Paulo, Brazil), placed on ice, and centrifuged at $3,000 \times g$ at $4^{\circ} \mathrm{C}$ for $30 \mathrm{~min}$. Serum was harvested and stored in microtubes at $-20^{\circ} \mathrm{C}$ until analysis. Progesterone concentration was determined using a chemiluminescent enzyme immunoassay (Immulite 1000; Siemens Medical Solutions Diagnostics, Los Angeles, CA). Intra- and interassay coefficient of variation were, respectively, 5.1 and $5.2 \%$. The minimum detectable concentration was $0.1 \mathrm{ng} / \mathrm{mL}$.

\section{Behavioral Data}

All cows carried an accelerometer (Afimilk Pedometer Plus Tag, Afimilk, Kibbutz Afikim, Israel) attached to 1 of the hind limbs within 1 wk of calving. Data were recorded in 2-h time bins, downloaded thrice daily by an electronic scanner at the milking parlor's entrance. 
Data were later retrieved from AfiFarm Dairy Farm Management Software (Afimilk) and compiled using Excel (Microsoft Corporation, Redmond, WA).

Lying behavior was recorded on a 24 -h basis $(0000$ to $2359 \mathrm{~h}$ ) and summarized as total lying time (L_time; min/d), bout frequency (bout_N; bouts/d), average lying bout duration ( $\mathrm{min} /$ bout), ratio of daily total lying time by total standing time, and restlessness, an Afimilk proprietary calculation measured in arbitrary units. Walking activity was obtained as average steps per hour within each of three 8-h sessions/d (0000-0759, 0800-1559, and 1600-2359 h).

\section{Data and Statistical Analyses}

These data are the result of an observational cohort study. Pregnancy diagnoses were performed for all 1,411 TAI events. However, ovulation, L_time, and bout_N were available for $773,1,211,1,209$ events, respectively. Statistical analyses were performed with SAS Studio University Edition ver. 3.1 (SAS Institute Inc., Cary, NC). Significance was set at a probability of type I error of $5 \%$, and tendencies between 5 and $10 \%$. Data were trimmed at the 1st and the 99th percentiles of L_time for each day (1st percentile $=279,168,126$, 126 , and $141 \mathrm{~min} / \mathrm{d}$ for $\mathrm{d}-7,-2,-1,0$ and $1 ; 99$ th percentile $=1,019,1,029,1,008,1,044$, and $1,074 \mathrm{~min} / \mathrm{d}$ for $\mathrm{d}-7,-2,-1,0$, and 1 , respectively).

Descriptive statistics were performed for each lying behavior variable. For objectivity of results and discussion, lying behavior was further analyzed regarding only L_time and bout_N, given that the calculation of daily total lying time by total standing time ratio includes L_time and that of the restlessness variable is not known, and because average lying bout duration was constant during the evaluated period. Least squares means and standard errors were obtained with proc MIXED of SAS (TAI event as subject and days as repeated measures). Three subgroups were observed regarding the day when behavior suggestive of estrus occurred $(\mathrm{d}-2,-1$, or 0$)$. For this reason, we present L_time and bout_N based on the lowest daily value among $\mathrm{d}-2,-1$ and 0 . The relative ratio between estrus and baseline for $\mathbf{L} \_$time\% and bout_N\% were calculated as (lowest L_time/baseline L_time) $\times 100$ and (lowest bout_N/baseline bout_N) $\times 100$, respectively.

Relative increase in walking activity was calculated using steps per hour within session at estrus and baseline days [(estrus steps $/ \mathrm{h}$ - baseline steps/h)/baseline steps $/ \mathrm{h}) \times 100]$. Estrus steps per hour were defined as the average steps per hour of the 8-h session with the greatest value among all sessions of $\mathrm{d}-2,-1$ and 0 . Baseline steps per hour represent the average steps per hour within the 8-h session that presented the greatest value on that day. Spearman rank correlations were calculated to evaluate the association between absolute measurements (L_time, bout_N, and steps/h) and relative measurements (L_time\%, bout_N\%, and relative increase in walking activity).

Associations between baseline $(\mathrm{d}-7)$ L_time or bout_N and season, parity, milk yield, and BCS were tested with SAS proc MIXED, using cow as repeated measures and event as the experimental unit. After testing for univariable associations and 2-way interactions, those with $P \leq 0.20$ were presented to final models, which included effects of parity, BCS, DIM, category of milk yield (mean of $d-3$ to 3 yield; $\leq$ mean or $>$ mean), as well as the interaction between parity and DIM in the model where L_time was the outcome variable. Results are presented as least squares means \pm standard error.

Ovulation rate and $\mathrm{P} / \mathrm{AI}$ at $\mathrm{d} 32$ post-AI were calculated for categories of L_time\% and bout_N\% (15-29,

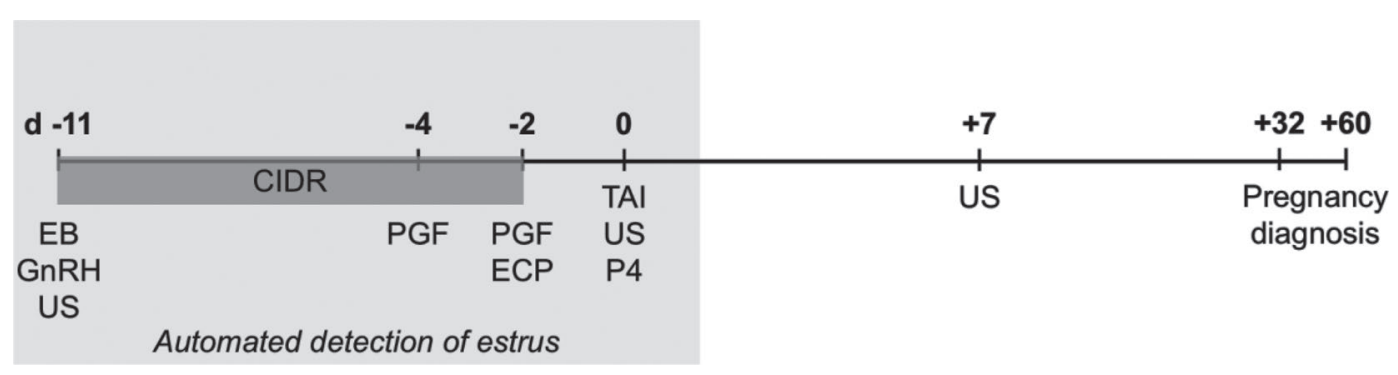

Figure 1. Experimental estrus synchronization protocol. $\mathrm{EB}=$ estradiol benzoate, $2 \mathrm{mg}$ (Gonadiol, Zoetis, São Paulo, Brazil); GnRH = gonadorelin diacetate, $100 \mu \mathrm{g}$ (Cystorelin, Merial, São Paulo, Brazil); PGF Pin $_{2}=$ dinoprost tromethamine, $25 \mathrm{mg}$ (Lutalyse, Zoetis); ECP = estradiol cypionate, $1 \mathrm{mg}$ (E.C.P., Zoetis); CIDR = intravaginal progesterone implant, $1.9 \mathrm{~g}$ of progesterone (CIDR, Zoetis); TAI = timed AI; $\mathrm{US}=$ examination of ovaries with ultrasonography; P4 = collection of blood sample for analysis of progesterone concentration. Lying behavior data were obtained at $\mathrm{d}-7$ (baseline) and $\mathrm{d}-2,-1$, and 0 (estrus) using Afimilk Pedometer Plus Tags and AfiFarm software (Afimilk, Kibbutz Afikim, Israel). 
Table 1. Distribution, realized fertility, and estrus characteristics according to day of lowest total lying time as percentage of baseline lying time

\begin{tabular}{|c|c|c|c|}
\hline \multirow[b]{2}{*}{ Item } & \multicolumn{3}{|c|}{ Day of lowest total lying time } \\
\hline & -2 & -1 & 0 \\
\hline Number of estrus events ( $\%$ of total events) & $133(11.8)$ & $569(50.7)$ & $421(37.5)$ \\
\hline Ovulation rate $(\%)$ & 66.7 & 91.2 & 84.0 \\
\hline $\mathrm{P} / \mathrm{AI}^{1}$ d $32(\%)$ & 16.5 & 32.0 & 31.6 \\
\hline $\mathrm{P} / \mathrm{AI}$ d $60(\%)$ & 15.8 & 27.8 & 27.7 \\
\hline \multicolumn{4}{|l|}{ Total lying time $( \pm$ SEM $)$} \\
\hline $\min / \mathrm{d}$ & $495.6 \pm 192.5$ & $423.1 \pm 142.5$ & $463.2 \pm 158.4$ \\
\hline$\%$ of baseline ${ }^{2}$ & $73.8 \pm 25.4$ & $61.2 \pm 19.3$ & $67.1 \pm 21.7$ \\
\hline \multicolumn{4}{|l|}{ Bout frequency $( \pm$ SEM $)$} \\
\hline Bouts/d & $9.7 \pm 5.1$ & $8.2 \pm 3.8$ & $8.6 \pm 4.0$ \\
\hline$\%$ of baseline ${ }^{3}$ & $73.3 \pm 27.7$ & $61.7 \pm 21.6$ & $66.6 \pm 24.5$ \\
\hline \multicolumn{4}{|l|}{ Walking activity $( \pm$ SEM $)$} \\
\hline Steps $/ \mathrm{h}$ & $523.7 \pm 326.4$ & $784.9 \pm 279.2$ & $679.7 \pm 294.7$ \\
\hline Relative increase $^{4}$ & $191.5 \pm 175.3$ & $336.9 \pm 151.9$ & $264.7 \pm 149.0$ \\
\hline \multicolumn{4}{|l|}{${ }^{1} \mathrm{P} / \mathrm{AI}=$ pregnancy per $\mathrm{AI}$} \\
\hline \multicolumn{4}{|c|}{$\begin{array}{l}{ }^{2} \text { Relative decrease in lying time: } \mathrm{L} \_ \text {time } \%=\left(\text { lowest } \mathrm{L} \_ \text {time} / \text { baseline } \mathrm{L} \_ \text {time }\right) \times 100 \text {, where } \mathrm{L} \_ \text {time }=\text { daily } \\
\text { total lying time. } \\
{ }^{3} \text { Relative decrease in bout frequency: bout_N } \%=(\text { lowest bout_N } / \text { baseline bout_N }) \times 100 \text {, where bout_N }= \\
\text { bout frequency. }\end{array}$} \\
\hline
\end{tabular}

30-44, 45-59, 60-74, 75-89, 90-104, and $\geq 105 \%$ ) using proc FREQ. Given the observed ovulation rate and $\mathrm{P} /$ AI within these categories, changes in L_time\% and bout_N\% were further classified as large if $<75 \%$ and small if $\geq 75 \%$. Events with lowest L_time $(\mathrm{n}=133)$ or bout_N ( $\mathrm{n}=201)$ occurring at $\mathrm{d}-2$ were excluded from the following analyses because of apparent poor response to the protocol and lack of synchronization with time of insemination, which would create a confounding effect especially within $\mathrm{P} / \mathrm{AI}$ results. Protocol response, lying behavior, and walking activity according to day of lowest L_time are shown in Table 1.

Multivariable logistic regression models (proc LOGISTIC) were built to test the probability of large change in lying behavior according to L_time\% or bout_N\% $(<75 \%)$, and probability of confirmed ovulation, pregnancy at $\mathrm{d} 32$, or pregnancy at $\mathrm{d} 60$, where TAI event was the experimental unit. The tested effects were parity (1st vs. 2nd and greater), DIM (1-60, $61-120,121-250$, and $\geq 251 \mathrm{~d}$ ), milk yield [mean of $\mathrm{d}$ -3 to 3 , tested as continuous and categorical forms $(\leq$ mean or $>$ mean)], CL at start of protocol (yes or no), BCS $(\leq 2.5,2.75-3.00$, and $\geq 3.25)$, progesterone concentration at TAI [tested in continuous and categorical forms $(\leq 0.09,0.10$ to 0.21 , or $\geq 0.22 \mathrm{ng} / \mathrm{mL})$ ], and season (colder: June to August; hotter: September and February to May). In addition to the explanatory variables mentioned above, the categories of estrus intensity (according to degree of change in L_time\% and bout_N\%) were individually tested as explanatory variables in models where the outcome was ovulation or P/AI. Explanatory variables were presented to multivariate logistic models using backward stepwise elimination at $P \leq 0.1$ and odds ratio (OR) and $95 \%$ confidence limits were obtained. Associations between explanatory and individual response variables were tested with Chi-squared test (proc FREQ). The final models for ovulation risk included effects of CL at start of protocol, category of milk yield, DIM and category of L_time\%, and effects of CL at start of protocol, category of milk yield, season, and category of bout_N\%. Final models for P/AI at 32 and 60 d included effects of parity, DIM, season, category of milk yield, and category of L_time\% or bout_N\%. The final model, where a large change in L_time\% was the outcome variable, included effects of category of milk yield; the model where bout_N\% was the outcome variable included effects of parity and season.

Events with relative increase in walking activity $\geq 100 \%$ were further classified as high-intensity estrus (relative change in walking activity $\geq 300 \%$ ) and lowintensity estrus (relative change in walking activity $<300 \%$ ), based on previous research (Madureira et al., 2015). Sensitivity and specificity for determination of magnitude of behavioral change at estrus were then calculated for L_time\% and bout_N\% based on relative increase in walking activity using the thresholds of $\geq 300 \%$ relative increase in walking activity as high-intensity estrus and $<75 \%$ change in L_time\% or bout_N\% as large behavioral change. Events were 
mutually classified according to relative increase in walking activity and L_time\% as high-large (HL), high-small (HS), low-large (LL), and low-small (LS). Associations between this mutual classification and likelihood of ovulation and $\mathrm{P} / \mathrm{AI}$ at $32 \mathrm{~d}$ were tested with proc LOGISTIC following the methodology described for the associations between measurements of fertility and lying behavior change. All contrasts between the 4 categories (HL, HS, LL, LS) were tested. In addition to effects of the mutual classification, the final models included DIM, category of milk yield, and CL at start of treatment, where ovulation was the response variable, and parity, DIM, category of milk yield, and season, where $\mathrm{P} / \mathrm{AI}$ at $32 \mathrm{~d}$ was the response variable.

\section{RESULTS}

\section{Cows and TAI Events}

At the TAI events $(\mathrm{n}=1,411)$, cows were $137 \pm 93$ DIM, had mean $( \pm \mathrm{SD})$ milk production of $43.6 \pm 11.0$ $\mathrm{kg} / \mathrm{d}$, and median BCS of 2.75 (17\% of cows $\leq 2.5,67 \%$ with BCS 2.75 or 3.00 , and $16 \%$ with BCS $\geq 3.25$ ). Primiparous represented $40.8 \%$ and multiparous (maximum 8 lactations) $59.2 \%$ of the enrolled cows. Fifty-two percent of TAI corresponded to first AI, $16 \%$ to second $\mathrm{AI}$, and $32 \%$ to third or greater AI.

\section{Daily Lying Behavior and Walking Activity During Estrus and Baseline}

At baseline $(\mathrm{d}-7)$, mean $( \pm \mathrm{SD})$ L_time was $695 \pm$ $124 \mathrm{~min} / \mathrm{d}$, bout_N was $13 \pm 5$ bouts/d, and walking activity was $185.4 \pm 44.8$ steps $/ \mathrm{h}$. Baseline L_time was affected by the interaction of parity and DIM (Figure 2a; $P=0.01$ ), and decreased by 1.22 min with every 1 -kg increase in milk yield $(P=0.002)$. Cows with high BCS had greater L_time $(728 \pm 10$ vs. $693 \pm 6$ and 663 $\pm 10 \mathrm{~min} / \mathrm{d}$ for high, medium, and low BCS, respectively; $P<0.001$ ) as well as greater bout_N at baseline (Figure 2b; $P<0.001$ ). Primiparous had greater baseline bout_N than multiparous $(14.6 \pm 0.31$ vs. $13.2 \pm$ $0.27 ; P<0.0001)$.

Daily L_time and bout_N within subgroups (lowest L_time or bout_N at $\mathrm{d}-2,-1$ or 0 ) are presented in Figure 3. Overall lowest L_time was $446.7 \pm 157.1$ $\mathrm{min} / \mathrm{d}$, equivalent to $64.9 \pm 21.4 \%$ of baseline L_time. Lowest bout_N occurred at d $-2,-1$, and 0 for 18.0, 51.0 , and $31.0 \%$ of events, respectively. Overall lowest bout_N was $8.5 \pm 4.0$ bouts/d, representing 64.9 $\pm 23.8 \%$ of baseline bout_N. Seventy-three percent of events had lowest L_time and lowest bout_N occurring at the same day.

\section{Risk Factors for Ovulation and P/AI}

Figure 4 shows ovulation rate and $\mathrm{P} / \mathrm{AI}$ across 7 categories of lowest L_time\% and lowest bout_N\%. Using these data as reference, we classified estrus into categories of large and small change in lying behavior (large if $\mathrm{L} \_$time or bout_n $<75 \%$ of baseline; small if $\mathrm{L} \_$time or bout_n $\geq 75 \%$ of baseline).

Based on L_time\%, odds of ovulation were greater when a CL was present at start of protocol [vs. absence of CL at start of protocol; OR $=3.62(95 \%$ confidence limit $=1.96-6.69), P<0.0001]$, when milk yield was above average [vs. below average; $\mathrm{OR}=2.03(1.11-3.71)$, $P=0.02]$, and when the change in L_time\% at estrus was large [vs. small change; $\mathrm{OR}=4.86(2.69-8.80)$; Figure 5]. Odds of ovulation were also affected by DIM $(P=0.04)$.

A large change in bout_N\% was associated with greater likelihood of ovulation $[\mathrm{OR}=2.06(1.11-3.83)$;
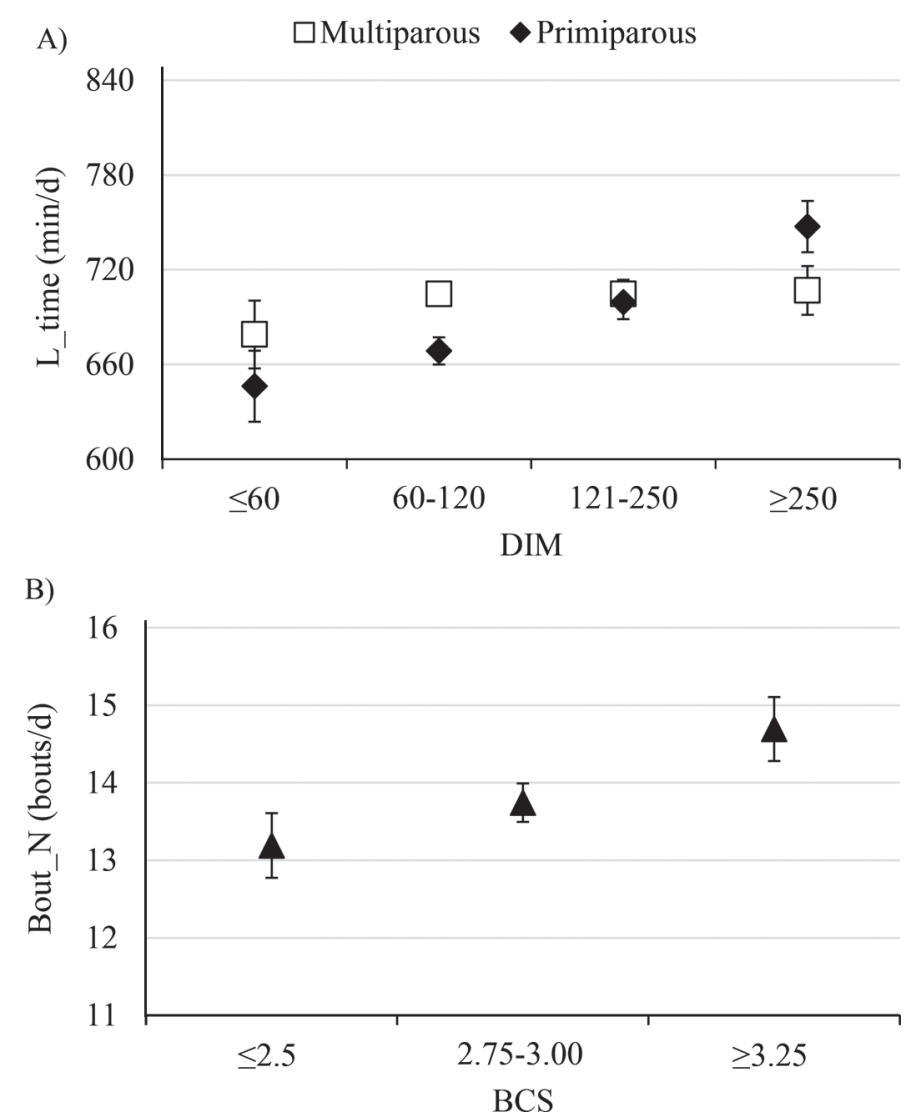

Figure 2. Baseline lying behavior of lactating Holstein cows, $7 \mathrm{~d}$ before timed AI. (A) Total lying time (L_time; min/d) according to parity (primiparous and multiparous) and categories of DIM $(\leq 60,61-$ $120,121-250$, and $\geq 251$ DIM; $P=0.01$ ); (B) bout frequency (bout_N; bouts/d) according to BCS $(P=0.01)$. Error bars indicate SEM. 
$P=0.02$; Figure 5]. Within the bout_N\% model, ovulation was more likely among cows with a CL at start of protocol $[\mathrm{OR}=4.17(2.18-7.98) ; P<0.0001]$ and for estrus occurring in the colder season $[\mathrm{OR}=1.97$ (1.02-3.83); $P=0.04]$. Ovulation tended to be more likely within the group of cows with milk yield above average $[\mathrm{OR}=1.76(0.96-3.22) ; P=0.07]$.

Table 2 contains OR and $95 \%$ confidence limits for variables affecting $\mathrm{P} / \mathrm{AI}$ at $\mathrm{d} 32$ in the model composed with L_time\%. Similar to the model with L_time\%, odds of P/AI at $32 \mathrm{~d}$ in the model with bout_N\% were influenced by parity, DIM, season, and milk yield $(P<$ $0.05)$, as well as by bout_N\%, where a large decrease in bout_N\% was associated a likelihood of $\mathrm{P} / \mathrm{AI}$ of $1.57(1.05-2.34 ; P=0.03)$. Greater odds of $\mathrm{P} / \mathrm{AI}$ at d 32 were observed following estrus with large change in both L_time\% and bout_N\% (Figure 6). At $60 \mathrm{~d}$, there was a tendency for an association between large change in lying behavior and greater likelihood of $\mathrm{P} / \mathrm{AI}$

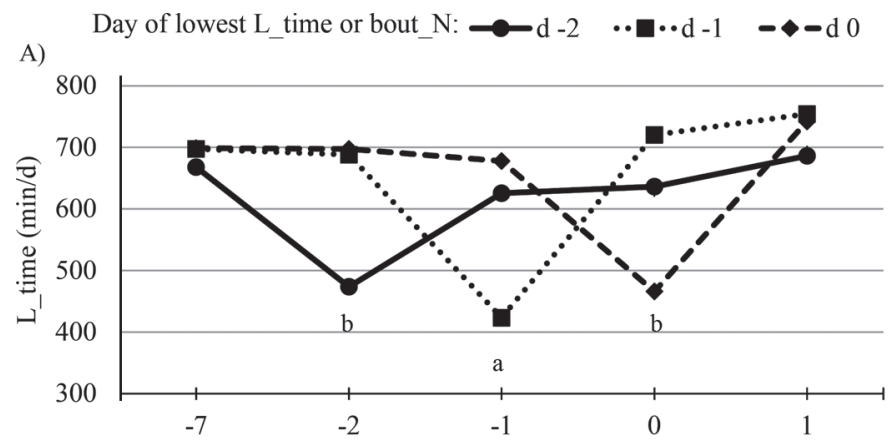

B)

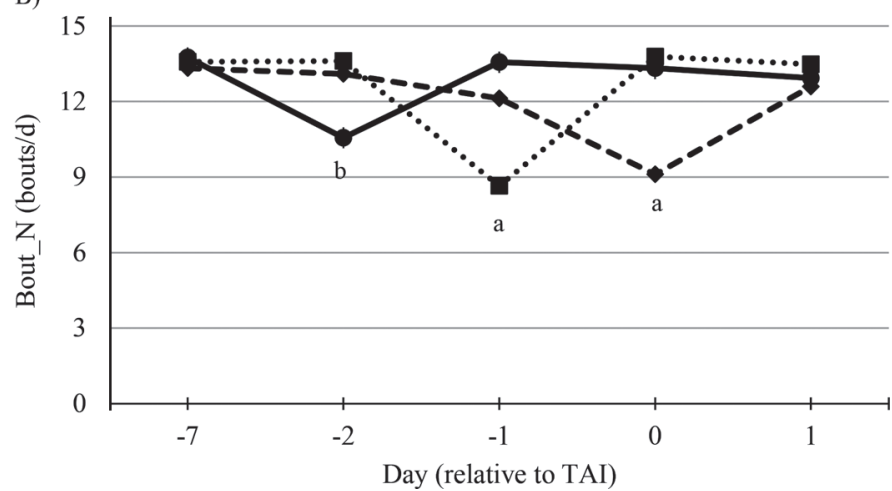

Figure 3. Daily total lying time (L_time; $\min / \mathrm{d}$ ) and bout frequency (bout_N; bouts/d) relative to timed AI (d 0). Different lines represent 3 subgroups of cows with lowest total lying time or bout frequency at $\mathrm{d}-2,-1$ or 0 . $P$-values for effect of day, subgroup and their interaction were $<0.0001$ (L_time), and $<0.0001,0.03$, and $<0.0001$ (bout_N). Different letters (a,b) within chart indicate statistical difference between the lowest value of each subgroup. Lying behavior was measured by accelerometers (Afimilk Pedometer Plus Tag, Afimilk, Kibbutz Afikim, Israel).
[L_time\%: OR $=1.46(0.99-2.15), P=0.06$; bout_N\%: $\mathrm{OR}=1.50(0.99-2.26), P=0.06$; Figure 5b]. Parity, DIM and milk yield also influenced P/AI at d $60(P<$ $0.05)$. When only cows that had a confirmed ovulation were included in the analysis of risk factors for $\mathrm{P} / \mathrm{AI}$ at 32 and $60 \mathrm{~d}$, there were significant effects of parity, DIM, and bout_N\% $(P<0.05)$ and a tendency for greater likelihood of $\mathrm{P} / \mathrm{AI}$ during the colder season $(P$ $=0.08)$. The L_time\% did not affect the likelihood of pregnancy in this circumstance $(P=0.20)$.

\section{Factors Affecting the Likelihood of Large Change in Lying Behavior at Estrus}

Milk yield above average reduced the likelihood of large change in L_time\% at estrus $[\mathrm{OR}=0.66(0.47-$ $0.92) ; P=0.01 ; 75.1$ vs. $68.2 \%$ large change in L_time\% for below-average and above-average yield cows], but other potential risk factors were not significant $(P>$ 0.05). Primiparous were more likely to show a large change in bout_N\% [OR $=1.75(1.21-2.53) ; P=0.003$; $77.2 \%$ of primiparous vs. $68.1 \%$ of multiparous had a large change in bout_N\% at estrus]. Likelihood of large change in bout_N\% tended to be greater for estrus occurring during the warmer season compared with the colder season $[\mathrm{OR}=1.45(0.98-2.15) ; P=0.06]$.

\section{Associations Between Lying Behavior and Walking Activity}

Spearman rank correlation coefficients between estrus walking activity (steps/h) and daily lying behavior were -0.38 and -0.26 for lowest L_time and lowest bout_N, respectively $(P<0.0001)$. Between the relative increase in walking activity and lying behavior, correlation coefficients were -0.38 (lowest L_time\%; $P$ $<0.0001$ ) and -0.31 (lowest bout_N\%; $P<0.0001$ ), respectively.

Lowest L_time\% had $82.5 \%$ sensitivity and $34.3 \%$ specificity for categorization of estrus intensity (relative increase in walking activity as gold standard). Lowest bout_N\% had $78.6 \%$ sensitivity and $40.1 \%$ specificity. Distribution of estrus intensity according to the mutual classification by relative increase in walking activity and L_time\% was $45.9 \% \mathrm{HL}, 9.7 \% \mathrm{HS}, 29.2 \% \mathrm{LL}$, and $15.2 \%$ LS $(\mathrm{n}=979)$.

We found no association between the mutual classification of events according to relative increase in walking activity and L_time\% on likelihood of ovulation $(P=0.17)$. Likelihood of $\mathrm{P} / \mathrm{AI}$ at $32 \mathrm{~d}$ was greater for events classified as HL and HS than for LS events [HL and HS: $\mathrm{OR}=1.85(1.09-3.13), P=0.02$; LS: 2.16 


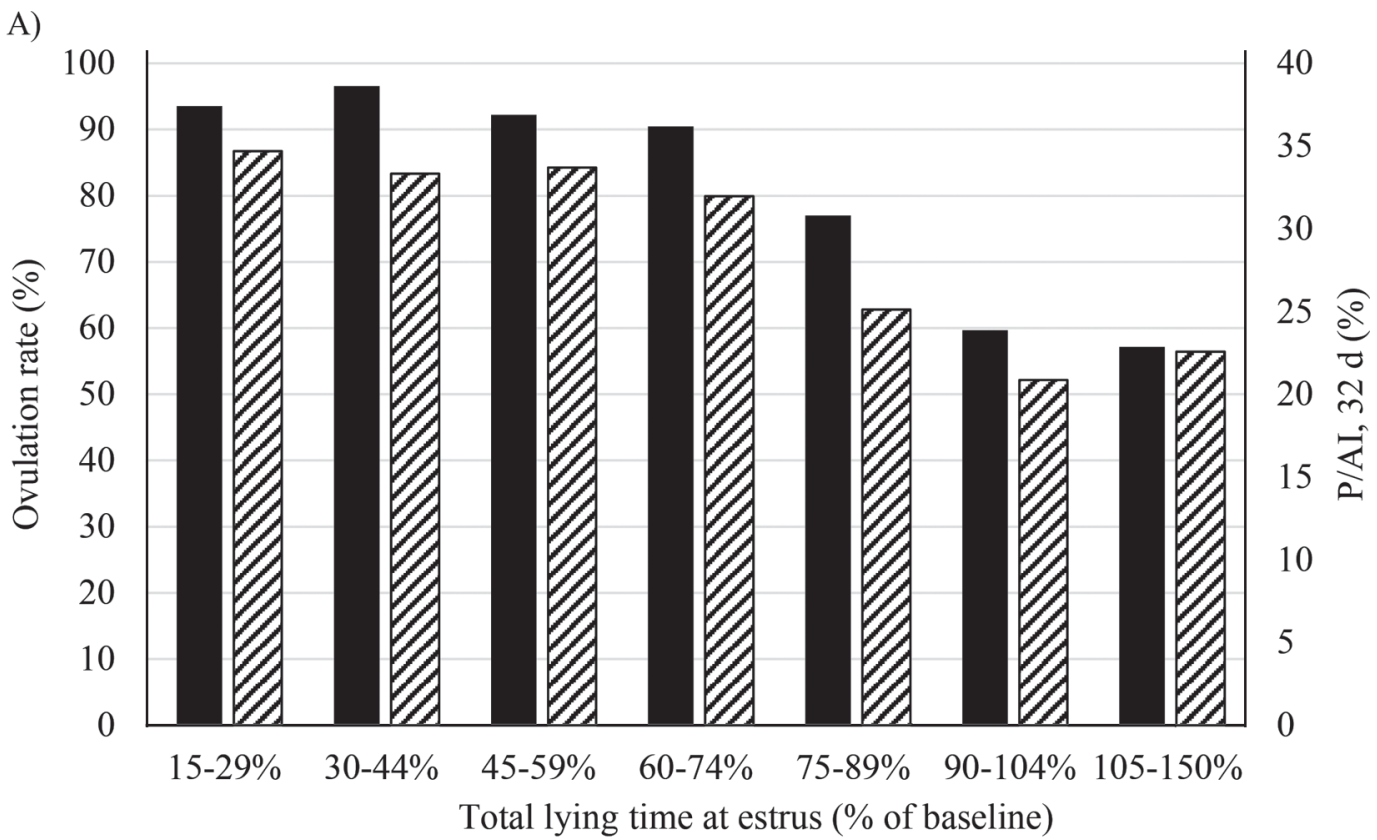

B)

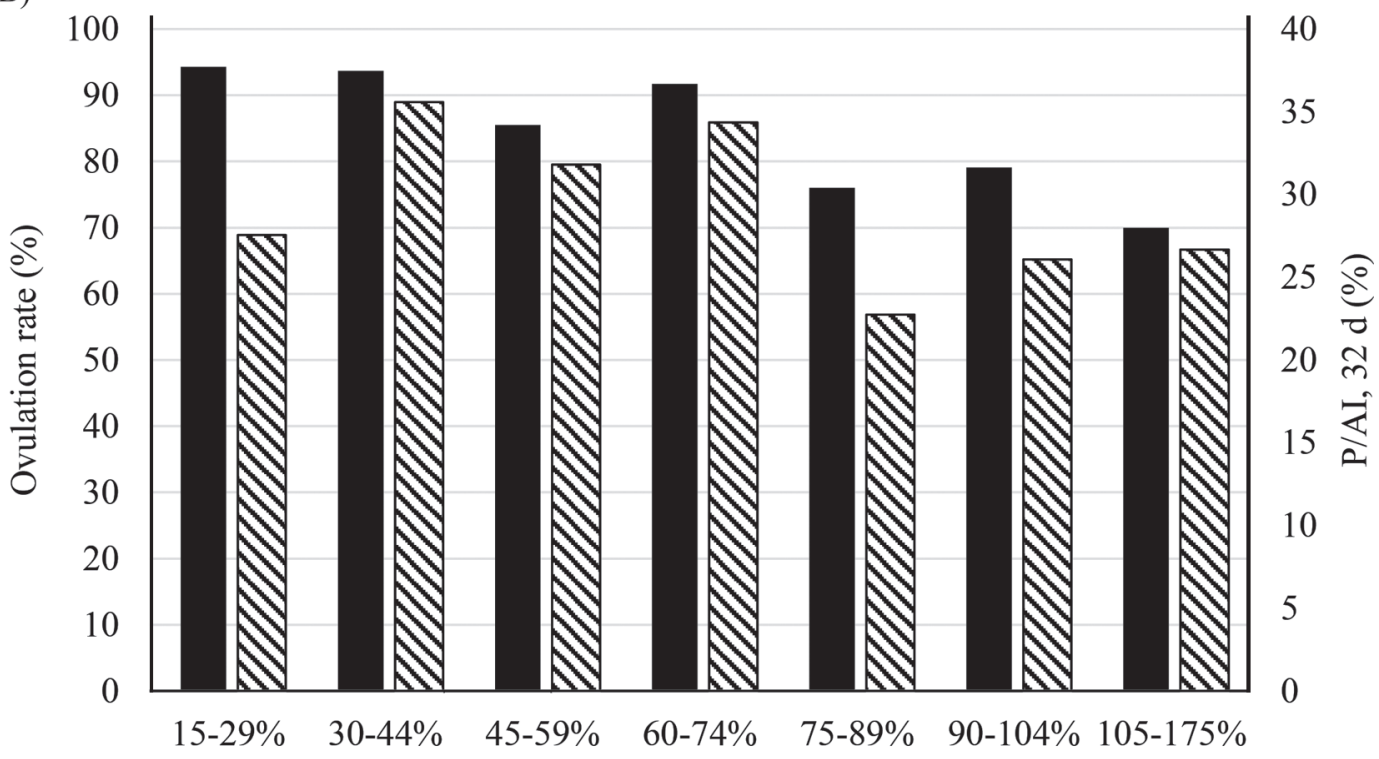

Bout frequency at estrus ( $\%$ of baseline)

Figure 4. Distribution of ovulation rate (\%; dark bars) and pregnancy per AI (P/AI, \%; dashed bars) according to relative change in total lying time at estrus (A) and relative change in bout frequency at estrus (B).

(1.10-4.23), $P=0.03]$, but it did not differ among HL and HS events $(P=0.57)$. High-large and HS events had greater likelihood of $\mathrm{P} / \mathrm{AI}$ at $32 \mathrm{~d}$ than LL events [HL and HS: 1.53 (1.04-2.24), $P=0.03 ; 1.78$ (1.01-3.15), $P=0.05]$. Low-large events were not different from LS events $(P=0.52)$. Pregnancy per AI at $32 \mathrm{~d}$ was 37.0, $42.1,28.7$, and $27.5 \%$ for HL, HS, LL, and LS events, respectively.

\section{DISCUSSION}

The results presented here provide supporting evidence for the association between the degree of behavioral change (intensity) of estrus expression and realized fertility after TAI, which has been recently reported for AI performed after detection of spontaneous estrus (Madureira et al., 2015). Although restlessness 
Table 2. Pregnancy per AI $32 \mathrm{~d}$ after AI (P/AI; \% and frequencies), odds ratio (OR and $95 \%$ confidence limits), and $P$-values referent to logistic regression model where estrus intensity (degree of behavioral change) was measured by L_time $\%^{1}$

\begin{tabular}{|c|c|c|c|}
\hline \multirow[b]{2}{*}{ Variable level } & \multicolumn{3}{|c|}{$\mathrm{P} / \mathrm{AI}^{2}$} \\
\hline & $\begin{array}{c}\% \\
\text { (no. pregnant/total no.) }\end{array}$ & $\begin{array}{c}\text { OR } \\
(95 \% \mathrm{CL})\end{array}$ & $P$-value \\
\hline \multicolumn{4}{|l|}{ Parity } \\
\hline 1 st & $38(159 / 423)$ & $1.68(1.21-2.34)$ & 0.002 \\
\hline 2nd or greater & $28(156 / 567)$ & Referent & - \\
\hline \multicolumn{4}{|l|}{ DIM } \\
\hline$<60$ & $32(17 / 53)$ & Referent & 0.005 \\
\hline$\overline{6} 1-120$ & $34(180 / 525)$ & $0.73(0.23-2.26)$ & - \\
\hline $121-250$ & $33(100 / 301)$ & $0.69(0.22-2.20)$ & - \\
\hline$\geq 251$ & $16(18 / 111)$ & $0.19(0.05-0.73)$ & - \\
\hline \multicolumn{4}{|l|}{ Milk yield $(\mathrm{kg} / \mathrm{d})$} \\
\hline$\leq 43.6$ & $31(146 / 477)$ & Referent & 0.06 \\
\hline$>43.6$ & $33(169 / 512)$ & $1.37(0.99-1.91)$ & - \\
\hline \multicolumn{4}{|l|}{ Season } \\
\hline Warm & $27(126 / 468)$ & Referent & 0.02 \\
\hline Cold & $36(189 / 522)$ & $1.55(1.08-2.22)$ & - \\
\hline \multicolumn{4}{|c|}{ Degree of change (based on L_time\%) } \\
\hline Small $(\geq 75 \%)$ & $26(74 / 283)$ & Referent & 0.01 \\
\hline Large $(<75 \%)$ & $34(241 / 707)$ & $1.61(1.11-2.35)$ & - \\
\hline
\end{tabular}

${ }^{1}$ Relative decrease in lying time: L_time\% = (lowest L_time/baseline L_time) $\times 100$, where L_time = daily total lying time.

${ }^{2}$ Only events with lowest lying time on $\mathrm{d}-1$ or 0 were considered in this analysis $(\mathrm{n}=990)$.

is widely recognized as one of the main signs of estrus (Roelofs et al., 2010), its lying behavior component has not been as extensively employed in the measurement of estrus behavior as physical activity has been. Factors influencing the relative decrease in lying time or

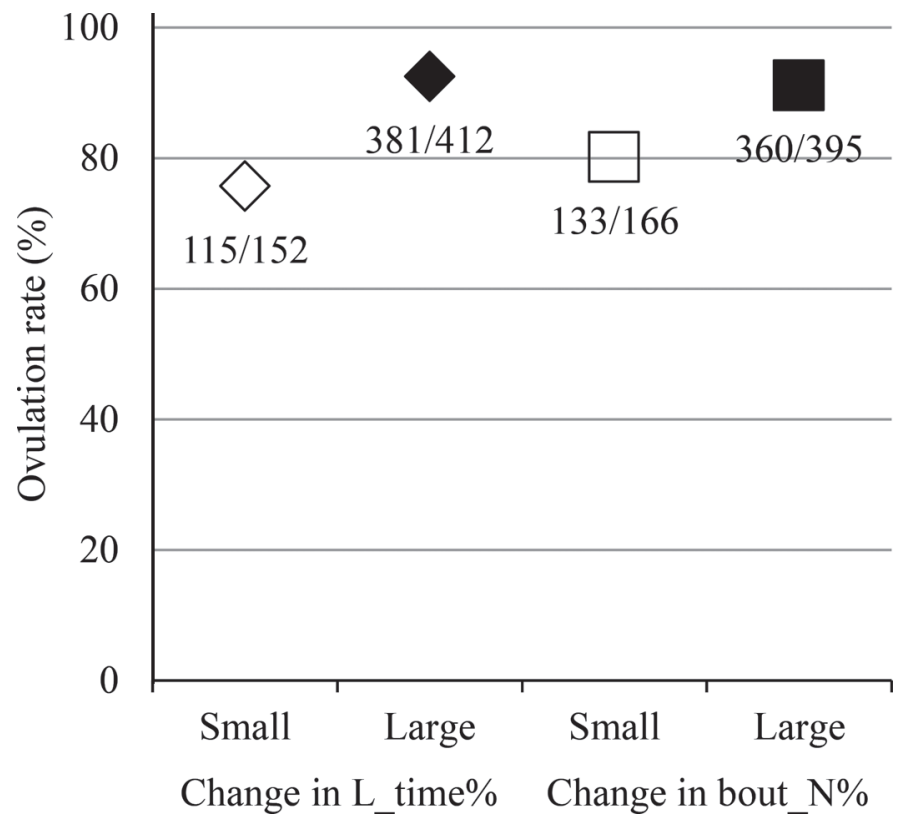

Figure 5. Rate of ovulation (\%) according to the relative change in lying time (L_time\%) and bout frequency (bout_N\%; low $\geq 75 \%$ baseline; high $<75 \%$ baseline). $P$-values were $<0.0001$ for $\mathrm{L} \_$time\% and 0.0003 for bout_N\%. bout frequency were similar to those affecting intensity of spontaneous estrus measured by physical activity (Madureira et al., 2015) and behavioral display of standing to be mounted (Lopez et al., 2004). Although our results show that lying behavior data are valuable to monitor dairy cow fertility, the analysis of a mutual classification (walking activity and lying time) showed that when the relative increase in walking activity is $\geq 300 \%$, which is associated with greater $\mathrm{P} / \mathrm{AI}$ at $32 \mathrm{~d}$ (Madureira et al., 2015), the degree of change in lying time does not further improve P/AI at $32 \mathrm{~d}$.

Changes in daily lying time of lactating cows during periods of estrus were similar to those observed for dairy heifers (Silper et al., 2015a), although baseline bout frequency was apparently greater and baseline daily lying time shorter for lactating cows. Lying behavior of lactating cows analyzed in minutes per hour and bouts per hour (Dolecheck et al., 2015) indicated a larger difference between baseline and estrus than that reported here. Although different AAM are often based in similar measurements, outcome differences could arise due to equipment precision, algorithms, and data processing, among other possible sources (Rutten et al., 2013). Baseline lying time and bout frequency were influenced by factors such as parity, DIM, and $\mathrm{BCS}$. Between-cow variation in lying time has been demonstrated to be large (overall 2.8 to $20.5 \mathrm{~h} / \mathrm{d}$; von Keyserlingk et al., 2012), which in addition to the large variation in estrus behavior (Silper et al., 2015b) supports the use of relative ratios as the measure of 
choice for automated estrus detection. These sources of variation should be investigated regarding a potential contribution to estrus expression; namely, provision of conditions for expression of baseline behavior in the opposite direction from estrus behavior could increase relative intensity of expression. For example, if cows with low BCS are likely to have reduced daily lying time, it cannot be expected that these cows will show a large relative decrease in lying time when in estrus.

The development of new technologies enables obtainment of diverse measurements from a single sensor and potentially greater accuracy of detection. As an example, Jónsson et al. (2011) showed increased probability of estrus detection and reduced error rate when combining walking activity and lying behavior. More studies are needed to address the applicability of lying behavior toward real-time estrus detection and determination of AI timing. Incorporation of lying time or bout frequency to estrus-detection systems

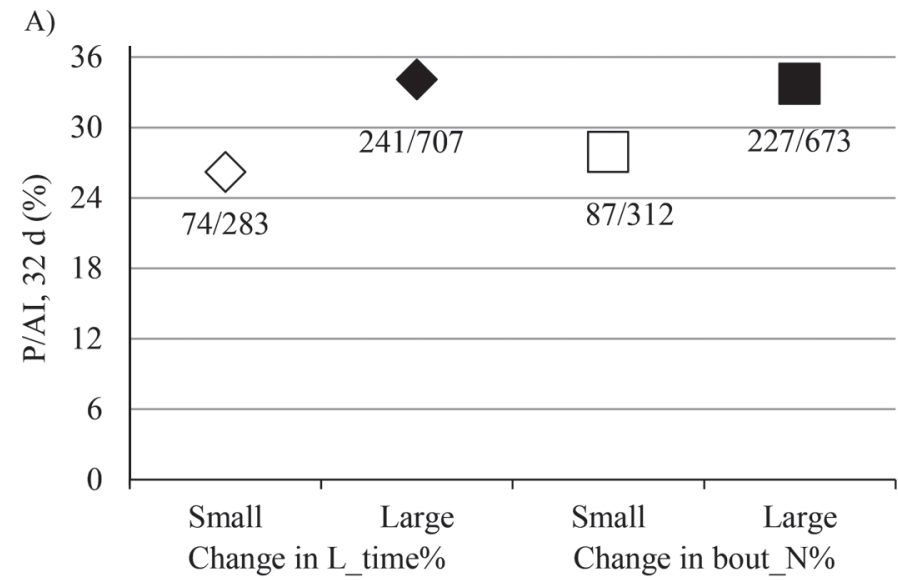

B)

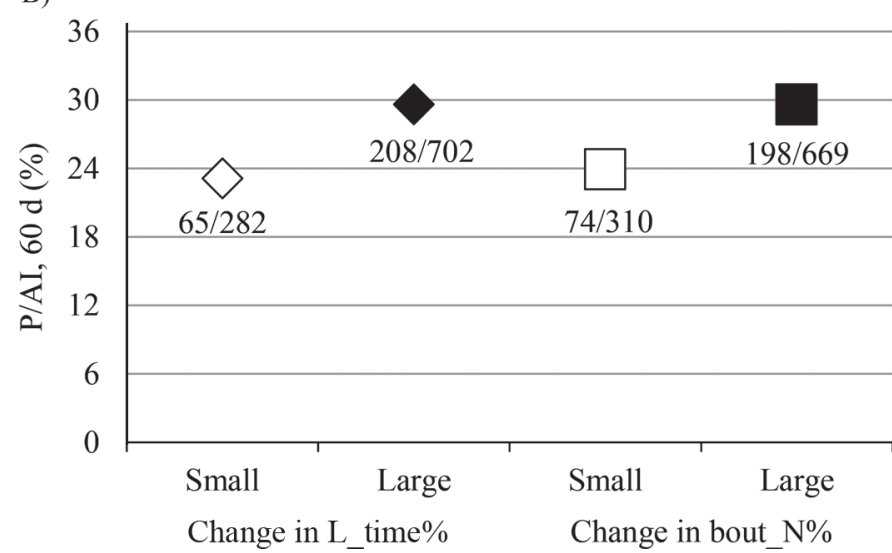

Figure 6. Pregnancy per AI (P/AI; \%) at d 32 and 60 after timed AI according to the relative change in lying time (L_time\%) and bout frequency (bout_N\%; low $>75 \%$ baseline; high $<75 \%$ baseline). P $/ \mathrm{AI}$ at d 32: $P=0.02$ (L_time\%) and $P=0.06$ (bout_N\%); P/AI at d 60: $P=0.04$ (L_time\%) and $P=0.06$ (bout_N\%). might be beneficial, as measurements of lying behavior and walking activity were not strongly correlated. Compared with the relative increase in walking activity as gold standard classification of estrus intensity, the categorization of relative change in for L_time\% and bout_N\% identified 17.5 and $21.4 \%$ false-negative highintensity events, respectively, and a larger proportion of false-positive high intensity events (65.8 and $59.9 \%$ for L_time\% and bout_N\%, respectively). The large proportion of false-positives supports the absence of strong correlation between the 2 measurements of behavior.

The association between estrus expression and fertility suggests underlying physiological mechanisms, where hormones such as estradiol and progesterone would coordinate estrus expression and also influence fertility-related parameters (e.g., ovulation, oocyte quality, uterine environment, CL function), as a positive effect of estrus on pregnancy after TAI and ET has been reported (Pereira et al., 2016). Following the same TAI protocol used in this experiment, Pereira et al. (2015) reported that $17 \%$ of cows did not show estrus behavior, but $62 \%$ of those cows ovulated in response to the protocol. Behavioral expression of estrus could differ between induced and spontaneous estrus, and synchronization protocols might induce greater ovulation rate in absence of estrus behavior; however, the association between fertility and expression of estrus has been observed for spontaneous and induced estrus (Madureira et al., 2015; Pereira et al., 2015).

The association between magnitude of the relative change in lying time or bout frequency at estrus and realized fertility after TAI is similar to that between walking activity and fertility described by Madureira et al. (2015) for spontaneous estrus. This suggests that both measurements of behavior are valuable predictors of realized fertility. Our results indicate, however, that lying behavior measurements are likely more useful as a refinement after estrus detection based on walking activity than as an estrus detection tool by itself, as shown by similar $\mathrm{P} / \mathrm{AI}$ at $32 \mathrm{~d}$ when high-intensity estrus events were also characterized by either large or small change in lying time. Nevertheless, these results reinforce the role of estrus expression on fertility of high-producing dairy cows and the potential use of such measurements for fertility prediction and benchmarking of estrus expression among herds. The contribution of lying behavior measurements to accuracy of estrus detection remain to be studied where gold standard measurements, such as plasma or milk progesterone, or standing to be mounted can be analyzed.

The physiological mechanisms linking estrus expression and fertility are not yet fully understood, partially due to the large variation in expression of estrus behavior and to the diverse factors influencing behavioral es- 
trus and fertility outcomes. Lower concentration of progesterone during the luteal phase preceding estrus has been associated with precocious endometrial expression of estradiol receptors $\alpha$, leading to increased $\mathrm{PGF}_{2 \alpha}$ secretion and short estrous cycles (Cerri et al., 2011b), as well as a lower preovulatory estradiol concentration has been associated with precocious luteolysis (Mann and Lamming, 2000). High milk yield has been reported to affect duration of estrus, mediated by elevated steroid metabolism and low plasma estradiol concentration (Wiltbank et al., 2006). Although we observed reduced likelihood of large change in L_time\% when milk yield was above average, we found no effect on bout_N\%. Greater milk yield was, however, associated with greater ovulation rate and P/AI at 32 d. Santos et al. (2009) emphasized the complexity of the associations between milk yield and reproductive performance, as low-yield cows could be affected by metabolic or infectious diseases that also affect reproductive function, whereas high-producing cows can be the among the healthiest in a given herd. Because relative change in lying behavior is a novel measurement of estrus intensity, associations with milk yield should be replicated.

The synchronization protocol used in this experiment relied on ECP injection for induction of estrus behavior and ovulation. Estrus onset and ovulation have been reported to occur $29 \pm 2$ and $55 \pm 3 \mathrm{~h}$ after ECP injection, respectively, as part of a Heatsynch protocol (Pancarci et al., 2002). Therefore, estrus events occurring at $\mathrm{d}-2$ (day of ECP injection) were not influenced by the exogenous estradiol and they likely correspond to lack of synchronization in response to the protocol. All cows were inseminated at d 0 , independent of estrus expression. Neves et al. (2012) reported that 26 to $44 \%$ of AI within an Ovsynch protocol were done after visually observed estrus in spite of fixed time AI. When a Heatsynch protocol was used, Cerri et al. (2004) observed greater P/AI for cows that expressed estrus and were inseminated to estrus before TAI compared with cows that did not express estrus and were inseminated at TAI. Twenty-two percent of cows expressing estrus in response to a Heatsynch protocol did so before TAI (Cerri et al., 2004), in accordance with data presented here. Moreover, estrus expression near AI can decrease pregnancy losses and significantly improve fertility in cows submitted to embryo transfer (Pereira et al., 2016). The findings by Pereira et al. (2016) suggest that the beneficial effects of estrus are beyond improvements in ovulation rate, most likely affecting the endometrial environment and consequent maintenance of the embryo and fetus. In the present study, we could not determine if the realized fertility of $\mathrm{d}-2$ estrus events would be improved if insemination had been performed in a timely manner. Determination of insemination time according to estrus during a synchronization protocol could have potential to improve overall results, especially with estradiol and progesterone-based protocols, which induce estrus expression in a significant proportion of cows. Concomitant use of synchronization protocols and AAM should allow for such improvements.

One aspect regarding the study of intensity of estrus expression is the generation of practical information for on-farm use. Our results and those in the literature support the use of estrus intensity for fertility prediction and incorporation into decision-making features on AAM user interfaces, which are still lacking (Rutten et al., 2013). Limitations of the current study that remain to be investigated are the contribution of lying behavior measurements to accuracy of estrus detection and as a primary tool for generation of estrus alerts, and the characterization of lying behavior associated with spontaneous events of estrus. A second aspect of measurement of estrus intensity concerns its association with fertility. In this experiment, lying behavior proved to be associated with fertility, as previously reported for physical activity (Madureira et al., 2015). Automated physical activity measurements have been shown to be heritable and to be genetically correlated with interval from calving to first postpartum high-activity event (Ismael et al., 2015). In addition, research has shown that genetic merit for fertility is associated with degree of estrus physical activity as well as aspects of ovarian dynamics and progesterone concentration (Cummins et al., 2012), suggesting that automated behavioral evaluations could be an important phenotypical maker for fertility.

\section{CONCLUSIONS}

The assessment of lying behavior in association with fertility, where a larger decrease in lying time or bout frequency was associated with greater likelihood of ovulation and P/AI, provides evidence for the role of estrus expression in reproductive physiology. The relationship between estrus intensity and fertility still requires further understanding; nonetheless, application of intensity classification as part of decision-making tools represents an opportunity for improved use of sensors and reproductive performance when TAI protocols are used. However, the associations between lying behavior and fertility following spontaneous estrus remain to be addressed. Baseline lying behavior, which was influenced by factors such as BCS and DIM, has a direct effect on the calculation of relative behavioral change. Thus, baseline behavior should be investigated regard- 
ing alternatives for increased estrus detection. Although lying behavior was markedly different at estrus and its degree of change was associated with fertility, the analysis in conjunction with walking activity suggests a larger effect of the latter on fertility.

\section{ACKNOWLEDGMENTS}

We are grateful to Fazenda Colorado (Araras, Brazil) and their personnel for contributing with this research project. We also thank CNPq-Science Without Borders program (Brasília, Brazil) for the funds provided to B. F. Silper and Mitacs Globalink Program (Ottawa, Canada) for funds provided to L. B. Polsky.

\section{REFERENCES}

Aungier, S. P. M., J. F. Roche, P. Duffy, S. Scully, and M. A. Crowe. 2015. The relationship between activity clusters detected by an automatic activity monitor and endocrine changes during the periestrous period in lactating dairy cows. J. Dairy Sci. 98:1666-1684. https://doi.org/10.3168/jds.2013-7405.

Cerri, R. L. A., R. C. Chebel, F. Rivera, C. D. Narciso, R. A. Oliveira, M. Amstalden, G. M. Baez-Sandoval, L. J. Oliveira, W. W. Thatcher, and J. E. P. Santos. 2011b. Concentration of progesterone during the development of the ovulatory follicle: II. Ovarian and uterine responses. J. Dairy Sci. 94:3352-3365. https://doi.org/ $10.3168 /$ jds.2010-3735.

Cerri, R. L. A., R. C. Chebel, F. Rivera, C. D. Narciso, R. A. Oliveira, W. W. Thatcher, and J. E. P. Santos. 2011a. Concentration of progesterone during the development of the ovulatory follicle: I. Ovarian and embryonic responses. J. Dairy Sci. 94:3342-3351. https:// doi.org/10.3168/jds.2010-3734.

Cerri, R. L. A., J. E. P. Santos, S. O. Juchem, K. N. Galvão, and R. C. Chebel. 2004. Timed artificial insemination with estradiol cypionate or insemination at estrus in high-producing dairy cows. J. Dairy Sci. 87:3704-3715. https://doi.org/10.3168/jds.S0022 $-0302(04) 73509-2$

Charlton, G. L., D. B. Haley, J. Rushen, and A. M. de Passillé. 2014. Stocking density, milking duration, and lying times of lactating cows on Canadian freestall dairy farms. J. Dairy Sci. 97:26942700. https://doi.org/10.3168/jds.2013-6923.

Cummins, S. B., P. Lonergan, A. C. O. Evans, and S. T. Butler. 2012 Genetic merit for fertility traits in Holstein cows: II. Ovarian follicular and corpus luteum dynamics, reproductive hormones, and estrus behavior. J. Dairy Sci. 95:3698-3710. https://doi.org/10 $.3168 /$ jds.2011-4976.

Dolecheck, K. A., W. J. Silvia, G. Heersche, Y. M. Chang, D. L. Ray, A. E. Stone, B. A. Wadsworth, and J. M. Bewley. 2015. Behavioral and physiological changes around estrus events identified using multiple automated monitoring technologies. J. Dairy Sci. 98:8723-8731. https://doi.org/10.3168/jds.2015-9645.

FASS. 1999. Guide for the Care and Use of Agricultural Animals in Agricultural Research and Teaching. 1st rev. ed. Federation of Animal Science Societies, Savoy, IL.

Ismael, A., E. Strandberg, M. Kargo, A. Fogh, and P. Løvendahl. 2015. Estrus traits derived from activity measurements are heritable and closely related to the time from calving to first insemination. J. Dairy Sci. 98:3470-3477. https://doi.org/10.3168/jds.2014-8940.

Jónsson, R., M. Blanke, N. K. Poulsen, F. Caponetti, and S. Højsgaard. 2011. Oestrus detection in dairy cows from activity and lying data using on-line individual models. Comput. Electron. Agric. 76:6-15. https://doi.org/10.1016/j.compag.2010.12.014.

Lopez, H., L. D. Satter, and M. C. Wiltbank. 2004. Relationship between level of milk production and estrous behavior of lactating dairy cows. Anim. Reprod. Sci. 81:209-223.
López-Gatius, F., P. Santolaria, I. Mundet, and J. L. Yániz. 2005. Walking activity at estrus and subsequent fertility in dairy cows. Theriogenology 63:1419-1429. https://doi.org/10.1016/j .theriogenology.2004.07.007.

Løvendahl, P., and M. G. G. Chagunda. 2010. On the use of physical activity monitoring for estrus detection in dairy cows. J. Dairy Sci. 93:249-259. https://doi.org/10.3168/jds.2008-1721.

Madureira, A. M. L., B. F. Silper, T. A. Burnett, L. Polsky, L. H. Cruppe, D. M. Veira, J. L. M. Vasconcelos, and R. L. A. Cerri. 2015. Factors affecting expression of estrus measured by activity monitors and conception risk of lactating dairy cows. J. Dairy Sci. 98:7003-7014. https://doi.org/10.3168/jds.2015-9672.

Mann, G. E., and G. E. Lamming. 2000. The role of sub-optimal preovulatory oestradiol secretion in the aetiology of premature luteolysis during the short oestrous cycle in the cow. Anim. Reprod. Sci. 64:171-180. https://doi.org/10.1016/S0378-4320(00)00205-0.

NRC. 2001. Nutrient Requirements of Dairy Cattle. 7th rev. ed. Natl Acad. Press, Washington, DC.

Neves, R. C., K. E. Leslie, J. S. Walton, and S. J. LeBlanc. 2012 Reproductive performance with an automated activity monitoring system versus a synchronized breeding program. J. Dairy Sci. 95:5683-5693. https://doi.org/10.3168/jds.2011-5264.

Pancarci, S. M., E. R. Jordan, C. A. Risco, M. J. Schouten, F. L. Lopes, F. Moreira, and W. W. Thatcher. 2002. Use of estradiol cypionate in a presynchronized timed artificial insemination program for lactating dairy cattle. J. Dairy Sci. 85:122-131. https:// doi.org/10.3168/jds.S0022-0302(02)74060-5.

Pereira, M. H. C., A. D. P. Rodrigues, R. J. De Carvalho, M. C. Wiltbank, and J. L. M. Vasconcelos. 2014. Increasing length of an estradiol and progesterone timed artificial insemination protocol decreases pregnancy losses in lactating dairy cows. J. Dairy Sci. 97:1454-1464. https://doi.org/10.3168/jds.2013-7287.

Pereira, M. H. C., A. D. P. Rodrigues, T. Martins, W. V. C. Oliveira P. S. A. Silveira, M. C. Wiltbank, and J. L. M. Vasconcelos. 2013. Timed artificial insemination programs during the summer in lactating dairy cows: Comparison of the 5-d Cosynch protocol with an estrogen/progesterone-based protocol. J. Dairy Sci. 96:6904-6914.

Pereira, M. H. C., M. C. Wiltbank, L. F. S. P. Barbosa, W. M. Costa Jr., and M. A. P. Carvalho. 2015. Effect of adding a gonadotropinreleasing-hormone treatment at the beginning and a second prostaglandin F2a treatment at the end of an estradiol-based protocol for timed artificial insemination in lactating dairy cows during cool or hot seasons of the year. J. Dairy Sci. 98:947-959. https://doi .org/10.3168/jds.2014-8523.

Pereira, M. H. C., M. C. Wiltbank, and J. L. M. Vasconcelos. 2016. Expression of estrus improves fertility and decreases pregnancy losses in lactating dairy cows that receive artificial insemination or embryo transfer. J. Dairy Sci. 99:2237-2247. https://doi.org/10 $.3168 /$ jds.2015-9903

Roelofs, J., F. López-Gatius, R. H. F. Hunter, F. J. C. M. van Eerdenburg, and C. Hanzen. 2010. When is a cow in estrus? Clinical and practical aspects. Theriogenology 74:327-344. https://doi.org/10 $.1016 / \mathrm{j}$.theriogenology.2010.02.016.

Rutten, C. J., A. G. J. Velthuis, W. Steeneveld, and H. Hogeveen. 2013. Invited review: Sensors to support health management on dairy farms. J. Dairy Sci. 96:1928-1952. https://doi.org/10.3168/ jds.2012-6107.

Santos, J. E. P., H. M. Rutigliano, and M. F. Sá Filho. 2009. Risk factors for resumption of postpartum cyclicity and embryonic survival in lactating dairy cows. Anim. Reprod. Sci. 110:207-221. https:// doi.org/10.1016/j.anireprosci.2008.01.014.

Silper, B. F., L. Polsky, J. Luu, T. A. Burnett, J. Rushen, A. M. de Passillé, and R. L. A. Cerri. 2015a. Automated and visual measurements of estrous behavior and their sources of variation in Holstein heifers. II: Standing and lying patterns. Theriogenology 84:333-341. https://doi.org/10.1016/j.theriogenology.2014.12.030.

Silper, B. F., I. Robles, A. M. L. Madureira, T. A. Burnett, M. M Reis, A. M. de Passillé, J. Rushen, and R. L. A. Cerri. 2015b. Automated and visual measurements of estrous behavior and their sources of variation in Holstein heifers. I: Walking activity and 
behavior frequency. Theriogenology 84:312-320. https://doi.org/ 10.1016/j.theriogenology.2014.12.029.

Souza, A. H., A. Gümen, E. P. B. Silva, A. P. Cunha, J. N. Guenther, C. M. Peto, D. Z. Caraviello, and M. C. Wiltbank. 2007. Supplementation with estradiol-17 $\beta$ before the last gonadotropinreleasing hormone injection of the ovsynch protocol in lactating dairy cows. J. Dairy Sci. 90:4623-4634. https://doi.org/10.3168/ jds.2007-0172.

Spencer, T. E., R. C. Burghardt, G. A. Johnson, and F. W. Bazer. 2004. Conceptus signals for establishment and maintenance of pregnancy. Anim. Reprod. Sci. 82-83:537-550. https://doi.org/10 .1016/j.anireprosci.2004.04.014.

Stevenson, J. S., S. L. Hill, R. L. Nebel, and J. M. Dejarnette. 2014. Ovulation timing and conception risk after automated activity monitoring in lactating dairy cows. J. Dairy Sci. 97:4296-4308. https://doi.org/10.3168/jds.2013-7873.

Valenza, A., J. O. Giordano, G. Lopes, L. Vincenti, M. C. Amundson, and P. M. Fricke. 2012. Assessment of an accelerometer system for detection of estrus and treatment with gonadotropin-releasing hormone at the time of insemination in lactating dairy cows. J. Dairy Sci. 95:7115-7127. https://doi.org/10.3168/jds.2012-5639.

von Keyserlingk, M. A. G., A. Barrientos, K. Ito, E. Galo, and D. M. Weary. 2012. Benchmarking cow comfort on North American freestall dairies: Lameness, leg injuries, lying time, facility design, and management for high-producing Holstein dairy cows. J. Dairy Sci. 95:7399-7408. https://doi.org/10.3168/jds.2012-5807.

Wildman, E. E., G. M. Jones, P. E. Wagner, R. L. Boman, H. F. Troutt, and T. N. Lesch. 1982. A dairy cow body condition scoring system and its relationship to selected production characteristics. J. Dairy Sci. 65:495-501.

Wiltbank, M., H. Lopez, R. Sartori, S. Sangsritavong, and A. Gümen. 2006. Changes in reproductive physiology of lactating dairy cows due to elevated steroid metabolism. Theriogenology 65:17-29. https://doi.org/10.1016/j.theriogenology.2005.10.003. 